\title{
Almond Flower Development: Floral Initiation and Organogenesis
}

\author{
Bridget M. Lamp, ${ }^{1}$ Joseph H. Connell, ${ }^{2}$ Roger A. Duncan, ${ }^{2}$ Mario Viveros, ${ }^{2}$ and Vito S. Polito ${ }^{3}$ \\ Department of Pomology, University of California, Davis, CA 95616
}

\begin{abstract}
Additional INDEX words. Prunus dulcis, Prunus amygdalus, Amygdalus communis, scanning electron microscopy
Abstract. Scanning electron microscopy was used to examine almond [Prunus dulcis (Mill.) D.A. Webb (syn. Prunus amygdalus Batsch, Amygdalus communis L.)] flower bud development for three cultivars (Nonpareil, Carmel, and Butte) from four California locations (which span the range of almond production in California) for 2 years, and for 'Nonpareil' in a single location for a third year. The objectives were to document timing of floral developmental events and to better understand the extent of variation that exists within and among cultivars, locations, and years. Results indicated that the time of floral initiation relative to hull split varied among cultivars. Median time for floral initiation in 'Nonpareil' was more than 3 weeks after the onset of hull split. For 'Butte' and 'Carmel', median time of floral initiation preceded the onset of hull split. Extensive variation in the timing of bud development events within a cultivar was apparent. Timing of developmental events varied among locations, but no patterns emerged consistent with the north to south range which spanned $4^{\circ} 15^{\prime}$ latitude and $520 \mathrm{~km}$. Among years, development occurred earliest in 1997, a relatively warm year, and was delayed in 1998 and 1999 , relatively cool years. Results indicate an earlier onset of floral initiation than reported in the classical literature on the subject.
\end{abstract}

Almond [Prunus dulcis (syn. Prunus amygdalus, Amygdalus communis)] production in the United States occurs only in California, which produces $75 \%$ of the world's supply. Almonds comprise more acreage than any other fruit- or nut-tree crop in the state. The species is cultivated over a north to south range of $\approx 600 \mathrm{~km}$ and a latitude $>4^{\circ}$.

Almond flower buds are borne laterally in leaf axils on long shoots and short spurs. The flower buds enclose a single, terminal flower, and, typical of Prunus L. species, no leaves. One to several flower buds can form on a single spur.

Tufts and Morrow (1925) included 'Nonpareil' almond growing in Davis, Calif., in their classic study of flower bud development in rosaceous tree-crop species. They reported that almond flowers were initiated at the beginning of September, and sepal initiation did not occur until mid-September. They did not address differentiation events beyond these stages. Brooks (1940) examined the process of almond flower initiation and organogenesis in the context of deciphering morphological relations between carpels and leaves. $\mathrm{He}$ also looked at buds from 'Nonpareil' almond trees growing in Davis. The work emphasized morphological aspects and provides little discussion of timing.

More recent investigations have been conducted on other Prunus species Diaz et al.(1981) used scanning electron microscopy (SEM) to study the timing of flower development in sour cherry (Prunus cerasus L.) where the inflorescence meristem initiated flower primordia at the end of June, and the first signs of carpel initiation were evident by mid-September. Guimond et al. (1998) studied flower development in 'Bing' sweet cherry (Prunus avium L.) with

Received for publication 16 Aug. 2000. Accepted for publication 30 July 2001. This paper is a portion of a MS thesis submitted by B.M.L. The authors acknowledge the capable technical assistance of Katherine Pinney, Harold Becherer, Cara Cross, and Peggy Schrader, the cooperation of Chico State University, Chico, Calif., and Paramount Farms, Shafter, Calif., and the helpful advice of Tom Gradziel. This research was supported in part by a grant from the Almond Board of California. The cost of publishing this paper was defrayed in part by the payment of page charges. Under postal regulations, this paper therefore must be hereby marked advertisement solely to indicate this fact.

${ }^{1}$ Present address: University of California Botanical Garden, Berkeley, CA 94720.

${ }^{2}$ Extension advisor.

3Professor and corresponding author; e-mail vspolito@ucdavis.edu.
SEM. They compared pruned and nonpruned shoots, noting a difference in the timing of some developmental events involved in flowering. They also noted the possibility that differences exist among cultivars and among locations.

Warriner et al. (1985) studied the timing of flower initiation and the effects of environment and cultural practices on peach [Prunus persica (L.) Batsch (Peach Group)] flower initiation and development in Perkins, Okla. He observed no differentiation in flower buds by mid-July. The first evidence of initiation was in mid to late August. This was followed by flower organogenesis with pistil initiation occurring in mid-October. Bustamente-Garcia (1980) investigated 'Andross' peach from Winters, California where he found the first indications of floral initiation occurring in mid-July and pistil initiation in mid-September, 1 month earlier than Warriner et al. (1985). Raseira and Moore (1986) compared flower bud initiation in peach between northern and southern hemispheres. In

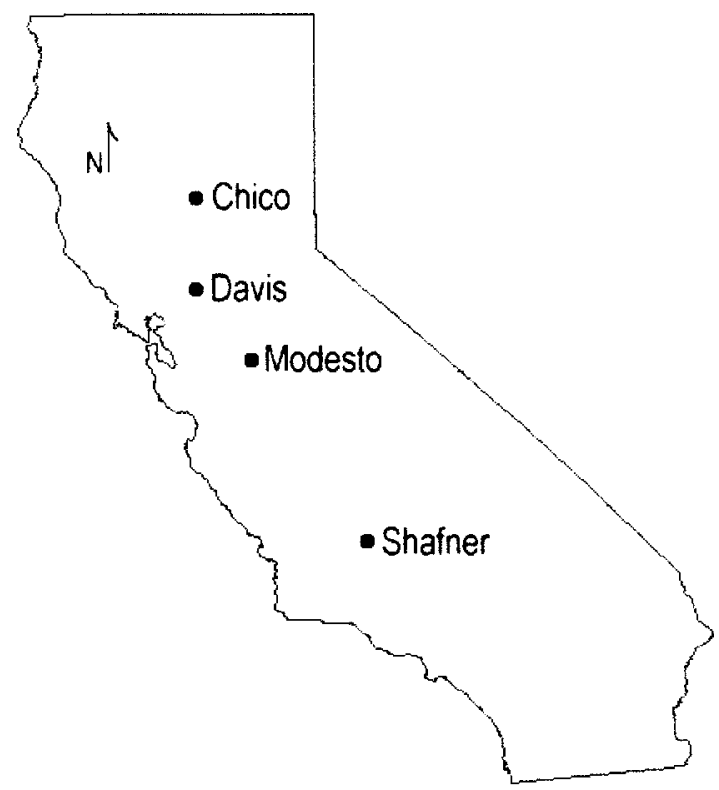

Fig. 1. Map of California showing the collection sites for the almond buds used in this research. 
both hemispheres, flower initiation occurred about the beginning of summer.

The present investigation involved two major objectives. The first was to document the timing of floral initiation and organogenesis in almond. The work of Tufts and Morrow (1925) is clearly obsolete, both in terms of methodology and in terms of the state of our understanding of the earliest morphological events of flower development. The study of Brooks (1940) focused primarily on morphological homologies between leaves and carpels, and is imprecise regarding the timing of events throughout the period of flower development and differentiation. Thus, almond researchers and orchard managers have no reliable information on the phenology of flower development.

The second objective was to document the extent of variation that occurs in the timing of flower developmental events within individual trees, among cultivars, and among years. Most previous work on tree-crop species acknowledges that such variation exists (see, for example, the works cited above), but little effort has been made to examine the extent of such variation. With regard to the timing of events within trees of the same cultivar, authors typically report their first observations of a particular stage. Variation within species has hardly been studied. Where cultivars within a species were examined under identical conditions by Luza and Polito (1988) and Polito and Pinney (1997) for walnut (Juglans regia L.) and Wetzstein and Sparks (1983) for pecan [Carya illinoinensis (Wangenh.) K. Koch], marked differences in timing of floral developmental events were found.

\section{Materials and Methods}

Starting mid-June in 1997, we collected shoots from the north and south sides of trees from well managed, commercial or research almond orchards in four locations within California (Fig. 1): Chico

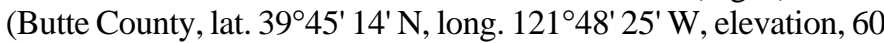

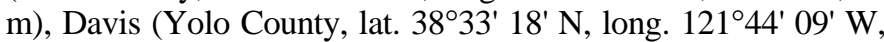
elevation, $15 \mathrm{~m}$ ), Modesto (Stanislaus County, lat. 37³9' 35' N, long. $120^{\circ} 59^{\prime} 38^{\prime} \mathrm{W}$, elevation, $27 \mathrm{~m}$ ), and Shafter (Kern County, lat. $35^{\circ} 30^{\prime} 04^{\prime} \mathrm{N}$, long. 119' 16' 22' W, elevation, $105 \mathrm{~m}$ ). These sites represent nearly the entire north to south range of almond production in California. Climatic conditions differ among these sites. Although all are located in California's Central Valley (comprising the Sacramento Valley to the north and the San Joaquin Valley to the south), the Chico and Shafter locations-near the northern and southern extremes of California almond production areas-are less influenced by moderating marine air that enters the valley at the San Francisco Bay.

Shoots from three cultivars-Nonpareil, Carmel, and Buttewere collected and examined. In 1997, 'Nonpareil' and 'Carmel' were collected weekly from Chico, Davis, and Modesto. 'Butte' was collected every fourth week at these sites, since 'Butte' is grown more commonly in the southern San Joaquin Valley. From Shafter, 'Nonpareil' and 'Butte' were collected weekly, and 'Carmel' was collected every fourth week for the same reason. Once sepal primordia were observed under the dissecting microscope, those cultivars that were collected every fourth week were collected weekly. In 1998, all three cultivars were collected every other week from all four locations. In 1999, 'Nonpareil' was collected weekly from Davis. For each collection, the north and south sides of the tree were sampled separately. For each year, collections were terminated when more than $75 \%$ of the dissected buds had pistils initiated. Shoots containing 1- and 2-year-old spurs were collected and shipped by overnight delivery service to the laboratory in Davis, Calif.

Buds were dissected by removing bud scales under a binocular microscope until the terminal meristem was visible at the shoot apex. The dissected shoot tips were excised from the shoot, fixed in $3 \%$ glutaraldehyde in $0.025 \mathrm{M}$ phosphate buffer at $\mathrm{pH} 6.8$, and stored at $4{ }^{\circ} \mathrm{C}$ for at least 3 weeks. After fixation, they were dehydrated in an ethanol series from $10 \%$ to $100 \%$ ethanol in $10 \%$ increments followed by three changes of $100 \%$ ethanol. The ethanol was replaced by amyl acetate in a dilution series: one change each of $50 \%$ and $75 \%$ amyl acetate in ethanol, and three changes of $100 \%$ amyl acetate. The shoot tips were critical-point dried using liquid $\mathrm{CO}_{2}$, mounted on aluminum stubs with adhesive or silver paint, coated with $30 \mathrm{~nm}$ gold in a sputtercoater (Bio-Rad Laboratories, Hercules, Calif.) and observed using a scanning electron microscope (ISI DS130; Intl. Scientific Instruments, Inc., Santa Clara, Calif.). Images were recorded digitally. For each collection, the number of buds at each of eight defined stages (see Results) was recorded. For each location, 20 buds from each side of the tree were dissected and fixed; however, the number of buds observed varied due to inevitable losses in preparation. Buds that were obviously necrotic or aborted were not scored.

Accumulated degree-days were calculated using a 10 to $27^{\circ} \mathrm{C}$ threshold from the full bloom date for each cultivar, at each location. A California Irrigation Management Information Services (CIMIS) networked weather station was the data source for each location (University of California Statewide Integrated Pest Management, 2000).

Statistical analyses were done using SAS (SAS Institute Inc., Cary, N.C.) procedures probit and logistic, and descriptive statistics were generated by SlideWrite Plus (Advanced Graphics Software, Inc., Encinitas, Calif.).

\section{Results and Discussion}

Almond flower bud differentiation was considered in eight stages (Table 1). Before flower initiation, the almond apical meristem is in the vegetative state, and produces bud scales (Stage 0, Fig. $2 \mathrm{~A})$. Flower initiation first becomes apparent at the shoot apex with

Table 1. Developmental stages of almond flower buds.

\begin{tabular}{lll}
\hline \hline Stage & Developmental stage & Developmental activity \\
\hline 0 & Vegetative (prereproductive) & Bud scales. \\
1 & Transition to reproductive state & Increase in meristem size. \\
2 & Flower initiation & Apex forms elongate, broad dome. Bracts present. \\
3 & Sepal initiation & Sequential initiation of five sepal primordia. \\
4 & Petal initiation & Sequential initiation of five petal primordia. \\
5 & Stamen initiation & Sequential initiation of multiple stamen primordia. \\
6 & Transitional/precarpel initiation & Stamen initiation complete, concavity at apex. \\
7 & Carpel initiation & Carpel visible at the center of the apex. \\
\hline
\end{tabular}


an increase in meristem size (Stage 1, Fig. 2B). The apex then becomes broadened and thickened to form an elongated, broad dome that produces bract primordia on the periphery of the apex (Stage 2, Fig. 2C). Typically, three bracts form to subtend the single, terminal flower that differentiates at the floral apex. Floral organogenesis begins with the initiation of five sepals. The sepal primordia arise in spiral phyllotaxis at the periphery of the terminal apex (Stage 3, Fig. 3A and B). Petal primordia are also initiated in spiral phyllotaxy, and arise alternate to the sepals within the calyx (Stage 4, Fig. 3C). Within the corolla, multiple stamens are initiated sequentially (Stage 5, Fig. 3D). As the calyx, corolla, and stamen bases grow to form the hypanthium, the floral apex becomes concave (Stage 6, Fig. 4A). Carpel initiation (Stage 7) begins with emergence of a single primordium at the periphery of the meristem (Fig. 4B). The primordium expands along the apical flank as the carpel margins develop. Subsequent development of the single carpel consumes the meristem apex entirely (Fig. 4C).

Temporal progress of flower differentiation for Stage 1 (transition to the reproductive state) and Stage 6 (transition to carpel initiation) is shown for each of the cultivars in each location in Table 2 (1997) and Table 3 (1998). Two measures of elapsed time are tabulated: days from bloom and accumulated degree-days from bloom. Figure 5 contrasts the patterns of degree-day accumulation for 1997-99 with the mean for the preceding 10-year period. Only data for Davis, Calif., are shown, but the other sites showed the same general pattern: 1997 was a relatively warm season, particularly early in the growing season, and 1998 and 1999 were relatively cool.

Data in Tables 2 and 3 show no consistent patterns among cultivars or locations. Differences between years do emerge, however. The relatively warmer 1997 correlates with earlier flower development than 1998.

There was extensive variation in the extent of bud development following floral initiation for a given cultivar in a given location. This is shown in Fig. 6 for 'Nonpareil' in 1997, a representative example. The bar-and-whisker plot illustrates the rate of attainment of each stage from floral initiation (Stage 1) to the transition to carpel initiation (Stage 6).

Progress of buds through Stages 1 and 6 for all cultivars and locations for 1997 and 1998 were fitted to probit and logistic regression models (SAS) using degree-days at 10 to $27^{\circ} \mathrm{C}$ thresholds. Analysesusing aspect (north vs. south side of tree) as a factor showed slight to no differences attributable to aspect so these data were pooled. Although both models had problems with nonconvergence that would have required larger samples sizes to correct, results indicate that location and cultivar effects are more important for Stage 6 development than for Stage 1 development (Table 4).

In an effort to determine if we could identify a correlation between externally visible events and timing of floral differentiation, the relationship between hull split (Micke et al., 1997, 1998) and the attainment of developmental Stages 1, transition to flowering and Stage 6, transition to carpel initiation, were examined (Table 5). For 'Nonpareil,' floral initiation occurred after hull split had begun; and, in all but one case, was complete by the time $90 \%$ of the hulls had split. The median time for buds reaching Stage 1 of

Fig. 2. Scanning electron micrographs of almond bud apices showing stages of development through floral initiation. (A) Stage 0. The apex terminates in a shoot apical meristem that produces vegetative organs, the bud scales. (B) Stage 1. This micrograph shows a shoot apical meristem in transition from the vegetative to reproductive condition. Note the increase in shoot apex diameter and elevation of the apex relative to the lateral organ primordia. (C) Stage 2. Transition to the reproductive state is complete. The floral apex and three bracts are shown. $\mathrm{Br}=$ bract; $\mathrm{BS}=$ bud scale; $\mathrm{FA}=$ floral apex; $\mathrm{SAM}=$, shoot apical meristem. Scale bars $=50 \mu \mathrm{m}$. development ranged from $5 \mathrm{~d}$ in Modesto for 1977 to $36 \mathrm{~d}$ in Shafter for 1997 after $10 \%$ of the hulls had split. Median time to floral
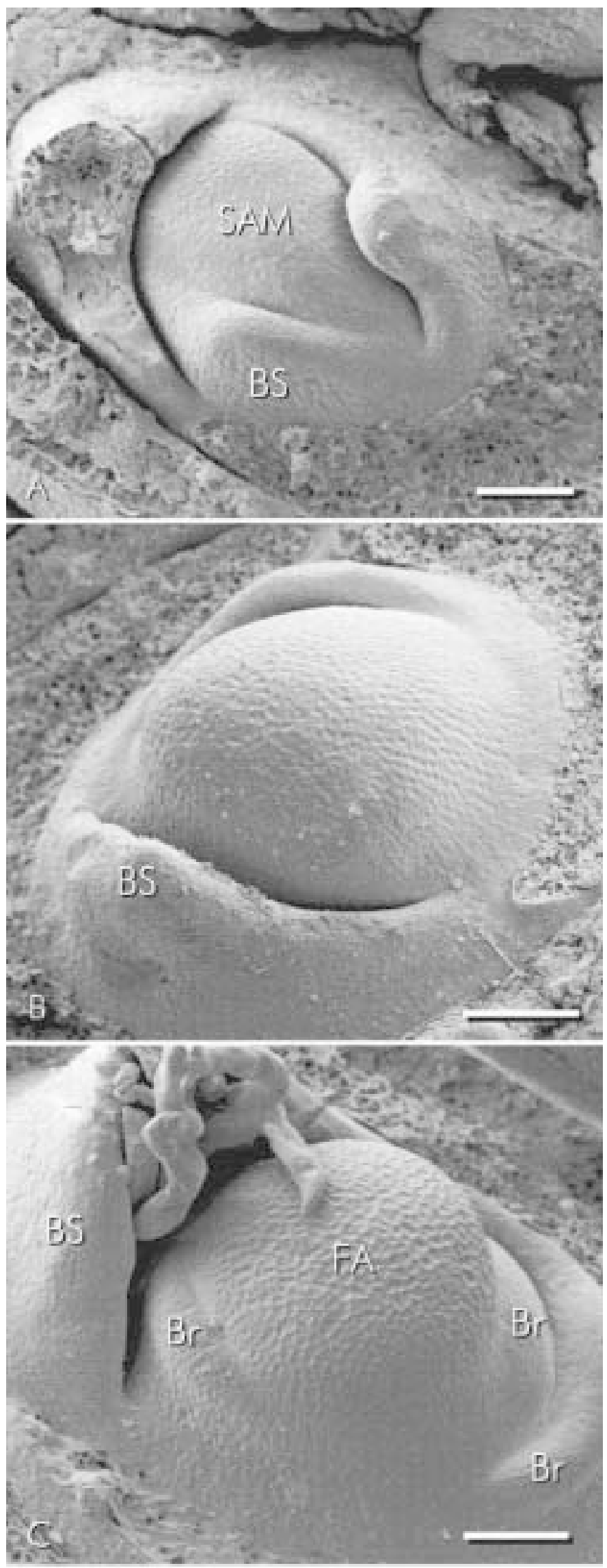
initiation for all locations in both years was $24 \mathrm{~d}$ after $10 \%$ hull split and $7.5 \mathrm{~d}$ before $90 \%$ hull spilt.

The situation for 'Carmel' and 'Butte' differed. For these cultivars, floral initiation preceded the onset of hull split. Floral initiation for 'Carmel' buds occurred a median of $23 \mathrm{~d}$ before $10 \%$ hull split, and for 'Butte' $13 \mathrm{~d}$ before $10 \%$ hull split. For these cultivars, the buds were in various stages of floral organ development at the time of hull split.

The morphological progress of flower bud differentiation in almond is similar to that of other Prunus species Flower initiation is manifested by changes in the size and shape of the shoot apical meristem which takes the form of a broad, low dome as it undergoes transition from a vegetative meristem to a reproductive meristem. This morphological stage is marked by a shift in organogenetic activity from bud-scale production to the sequential initiation of three bracts at the periphery of the meristem. In Prunus species with inflorescences containing several flowers, such as sweet cherry (Guimond et al., 1998) and sour cherry (Diaz et al., 1981), lateral flower primordia emerge in the axils of the bracts. In the solitaryflowered almond bud, the shoot apical meristem is converted to a terminal floral meristem with no developmental activity apparent in the axils of the bracts.

The early observations based on longitudinal sections by Tufts and Morrow (1925) for other rosaceous species, and by Brooks (1940) for almond, are generally similar to our observations using scanning electron microscopy. Tufts and Morrow (1925) described meristems of other species as broadening early in the path to floral organogenesis; however, they did not consider this stage in their discussion of almond. Brooks (1940) provided a description of these early stages of almond flower development. In the closely related peach. Warriner et al. (1985) described potentially floral apices as increasing in size at the onset of flower initiation. Similar observa-
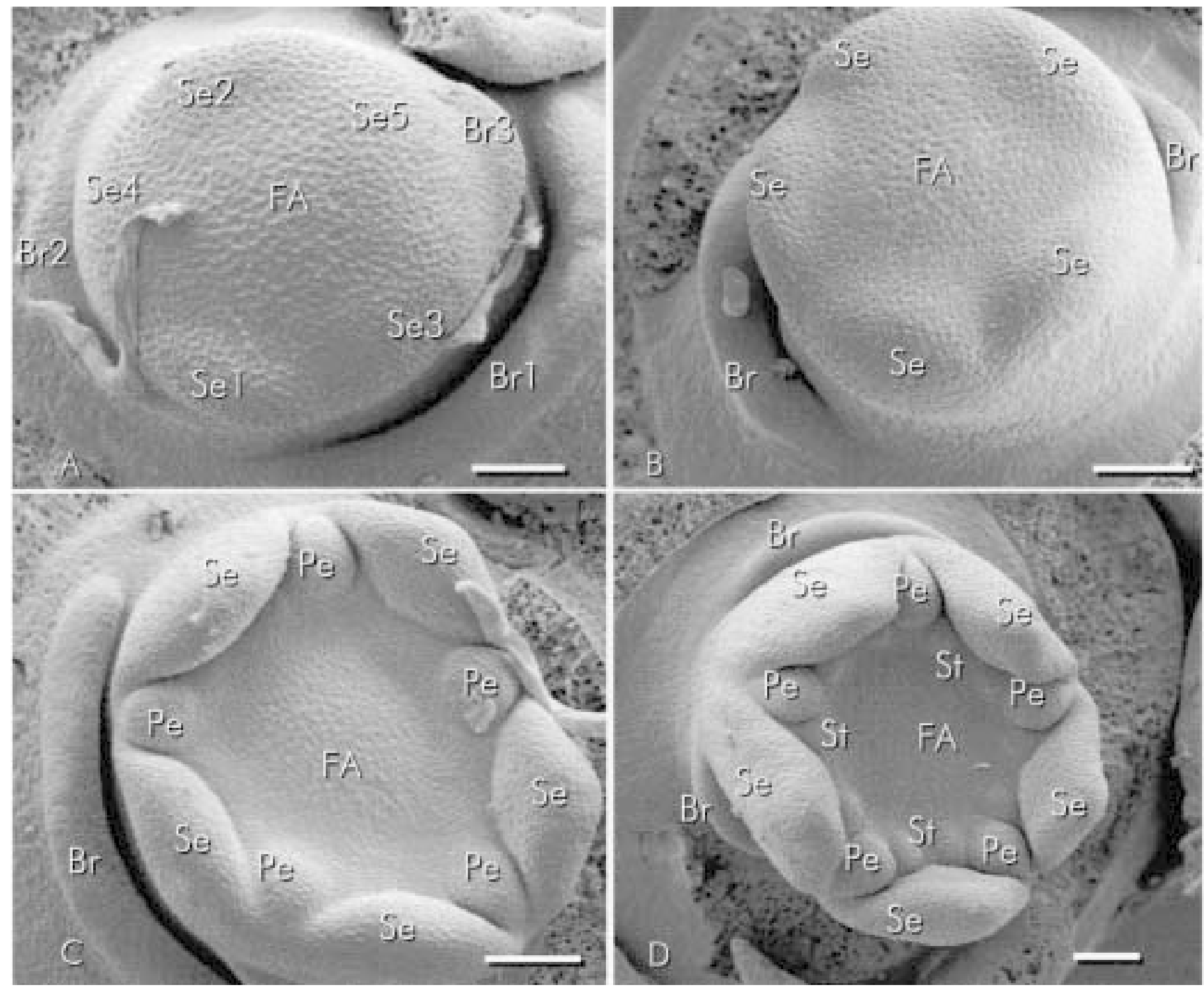

Fig. 3. Scanning electron micrographs of almond bud apices showing initiation of floral organs through stamen initiation. (A) Stage 3. Bract and sepal initiation at the floral apex follows a spiral phyllotaxy. The three bract primordia are numbered from the oldest to youngest (Br1-Br3). The sepal primordia are labeled similarly. The site of initiation of the final sepal primordium is indicated (Se5) but the primordium had not yet formed when this bud was dissected. (B) Stage 3. The floral apex, subtended by bracts, with initiation of the five sepal primordia complete. (C) Stage 4. Petal primordia form alternate to the sepal primordia. (D) Stage 5. The stamen primordia form acropetal to the petal primordia. Note the fused bases of the sepal, petal, and stamen primordia that form the hypanthium. $\mathrm{Br}=$ bract; $\mathrm{FA}=$ floral apex; $\mathrm{Pe}=$ petal; $\mathrm{Se}=$ sepal; $\mathrm{St}=$ stamen. Scale bars $=50 \mu \mathrm{m}$. 
tions were made for inflorescence initiation in sweet cherry (Guimond et al., 1998) as well as in other species more taxonomically remote
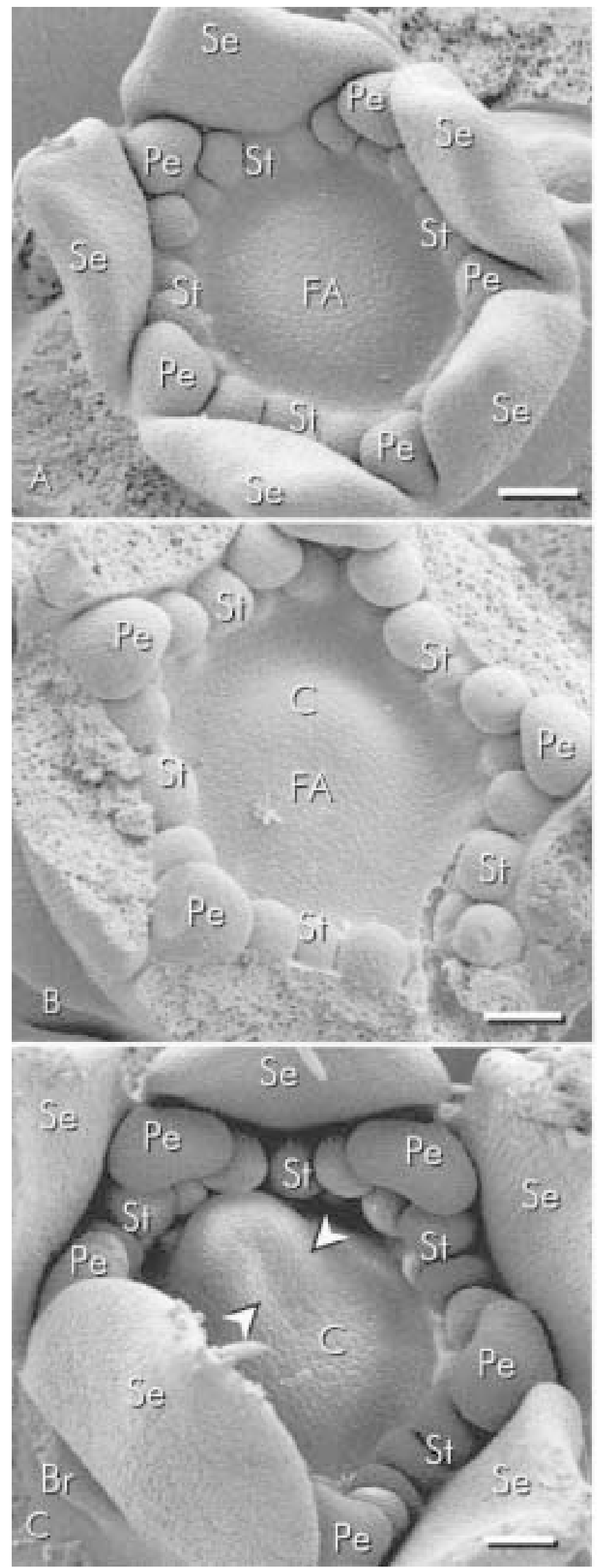

from almond, such as strawberry (Fragaria ×ananassa Duch.) (Taylor et al., 1997); Japanese pear (Pyrus serotina Rehd.) (Banno et al., 1985), and pecan (Wetzstein and Sparks, 1983).

The pattern of floral organogenesis following initiation is typical of other Prunoideae. However, previous work indicates that sepals and other floral organs are initiated simultaneously (Brooks, 1940). Our observations in almond show that this is not the case; sepal and petal primordia are initiated sequentially in spiral phyllotaxy (Fig. 3A). Taylor et al. (1997) show similar sequential initiation of sepals in strawberry flowers.

Tufts and Morrow (1925) reported the first indication of flower initiation as occurring on 1 Sept. in 'Nonpareil' flower buds in Davis. We observed flower initiation on 14 July 1997, 17 Aug. 1998, and 16 Aug. 1999 for the same cultivar at the same location. They reported having observed sepal initiation on $15 \mathrm{Sept}$. In our materials, sepal initiation occurred on 1 Aug. 1997, 31 Aug. 1998, and 26 Aug. 1999. Superficially, it appears that the timing of flower development occurred much earlier in 1997 and somewhat earlier in 1998 and 1999 as compared with the results of Tufts and Morrow (1925). However, when comparing the photomicrographs of Tufts and Morrow (1925) with our electron micrographs, it is apparent that the discrepancy lies primarily in the description of bud apex morphology and the interpretation of that morphology. The photomicrograph from a sample collected on 1 Sept. 1923, which Tufts and Morrow (1925) report as illustrating flower initiation, shows a floral meristem with sepal primordia initiated. The significance of earlier stages, which are now well known to indicate the onset of transition to reproductive development (see, for example, Bernier et al., 1981), was not well understood at that time, and Tufts and Morrow (1925) did not document their occurrence. Thus, it is their interpretation of the onset of floral organogenesis as representing floral initiation that accounts for the differences in the times they report for floral initiation and the results presented herein.

Similarly, Tufts and Morrow (1925) include a photomicrograph from a 15 Sept. 1923 collection to illustrate the stage that they consider as sepal initiation. This example shows evident petal primordia in addition to well developed sepals. The median dates for petal initiation in our material were 8 Aug. 1997, 14 Sept. 1998, and 10 Sept. 1999. Thus, for the two cooler years, the timing of petal initiation in our material is similar to that seen by Tufts and Morrow (1925). Tufts and Morrow (1925) did not follow the events of almond flower development past the initiation of primordial corolla organs.

Brooks (1940) studied almond flower development through carpel initiation. The situation he reports is similar to Tufts and Morrow (1925) in the timing of flower development. Brooks reported having observed flower initiation on $21 \mathrm{Aug}$. We saw this stage in mid-July in 1997, and mid-August in 1998 and 1999. Brooks reports that floral apices had developed further on 27 and 31 Aug., but had not yet undergone sepal initiation. However, the photomicrograph of Brooks (1940), representing this stage of flower initiation, appears to us to have sepal primordia present. He followed the stages of flower development, but is not specific in the timing of events after sepal initiation. He reported carpel initiation

Fig. 4. Scanning electron micrographs of almond bud apices showing initiation of the carpel. (A) Stage 6. Stamen primordia are present and the floral apex has not yet begun to differentiated a carpel primordium. (B) Stage 7. A terminal carpel primordium emerges at the periphery of the floral apex. Sepals have been removed in this sample. (C) Stage 7. As the terminal carpel primordium differentiates, it consumes the entire floral apex. Arrowheads indicate the carpel margins which will fuse to enclose the carpellary locule as differentiation progresses beyond this stage $\mathrm{Br}=$ bract $\mathrm{C}=$ carpel; $\mathrm{FA}=$ floral apex; $\mathrm{Pe}=$ petal; $\mathrm{Se}=$ sepal; $\mathrm{St}=$ stamen. Scale bars $=50 \mu \mathrm{m}$. 
Table 2. Median time from bloom to Stage 1 (transition to reproductive state) and Stage 6 (carpel initiation) of floral development and differentiation for three almond cultivars from four California locations in 1997.

\begin{tabular}{|c|c|c|c|c|c|c|c|}
\hline \multirow[b]{3}{*}{ Cultivar } & \multirow[b]{3}{*}{ Location } & \multicolumn{6}{|c|}{ Flower differentiation stage } \\
\hline & & \multicolumn{3}{|c|}{ Stage 1} & \multicolumn{3}{|c|}{ Stage 6} \\
\hline & & $\mathrm{DAB}^{\mathrm{z}}$ & $\mathrm{DD}^{\mathrm{y}}$ & $\mathrm{n}^{\mathrm{x}}$ & DAB & DD & $\mathrm{n}$ \\
\hline \multirow[t]{4}{*}{ Nonpareil } & Chico & 153 & 2173 & 106 & 202 & 3090 & 35 \\
\hline & Davis & 158 & 2140 & 101 & 207 & 3073 & 38 \\
\hline & Modesto & 156 & 1925 & 112 & 211 & 2983 & 57 \\
\hline & Shafter & 151 & 2094 & 92 & 218 & 3408 & 43 \\
\hline \multirow[t]{4}{*}{ Carmel } & Chico & 149 & 2109 & 26 & 187 & 2826 & 14 \\
\hline & Davis & 138 & 2102 & 21 & 178 & 2830 & 31 \\
\hline & Modesto & 145 & 1813 & 75 & 190 & 2609 & 15 \\
\hline & Shafter & 150 & 2092 & 26 & 182 & 2723 & 2 \\
\hline \multirow[t]{4}{*}{ Butte } & Chico & 168 & 2437 & 17 & 201 & 3074 & 22 \\
\hline & Davis & 165 & 2570 & 40 & 235 & 3898 & 63 \\
\hline & Modesto & 148 & 1890 & 21 & 206 & 2922 & 36 \\
\hline & Shafter & 169 & 2445 & 89 & 217 & 3379 & 36 \\
\hline
\end{tabular}

${ }^{\mathrm{z} D A B}=$ days after bloom

${ }^{\mathrm{y}} \mathrm{DD}=$ degree-days.

xTotal number of buds at stage.

Table 3. Median time from bloom to Stage 1 (transition to reproductive state) and Stage 6 (carpel initiation) of floral development and differentiation for three almond cultivars from four California locations in 1998.

\begin{tabular}{|c|c|c|c|c|c|c|c|}
\hline \multirow[b]{3}{*}{ Cultivar } & \multirow[b]{3}{*}{ Location } & \multicolumn{6}{|c|}{ Flower differentiation stage } \\
\hline & & \multicolumn{3}{|c|}{ Stage 1} & \multicolumn{3}{|c|}{ Stage 6} \\
\hline & & $\overline{\mathrm{DAB}^{\mathrm{z}}}$ & $\mathrm{DD}^{\mathrm{y}}$ & $\mathrm{n}^{\mathrm{x}}$ & DAB & $\mathrm{DD}$ & $\mathrm{n}$ \\
\hline \multirow[t]{4}{*}{ Nonpareil } & Chico & 183 & 2325 & 36 & 218 & 2914 & 12 \\
\hline & Davis & 180 & 2112 & 49 & 214 & 2699 & 23 \\
\hline & Modesto & 179 & 2126 & 51 & 279 & 2765 & 18 \\
\hline & Shafter & 170 & 2263 & 31 & 212 & 3044 & 14 \\
\hline \multirow[t]{4}{*}{ Carmel } & Chico & 177 & 2308 & 21 & 205 & 2801 & 15 \\
\hline & Davis & 170 & 1970 & 27 & 198 & 2467 & 22 \\
\hline & Modesto & 172 & 1966 & 47 & 206 & 2607 & 3 \\
\hline & Shafter & 164 & 2152 & 53 & 221 & 3174 & 21 \\
\hline \multirow[t]{4}{*}{ Butte } & Chico & 175 & 2298 & 32 & 210 & 2887 & 6 \\
\hline & Davis & 178 & 2189 & 50 & 220 & 2863 & 3 \\
\hline & Modesto & 189 & 2363 & 51 & 217 & 2744 & 15 \\
\hline & Shafter & 176 & 2451 & 42 & 204 & 3014 & 9 \\
\hline
\end{tabular}

${ }^{\mathrm{z}} \mathrm{DAB}=$ days after bloom.

${ }^{\mathrm{y}} \mathrm{DD}=$ degree-days.

${ }^{\mathrm{x}}$ Total number of buds at stage.

as occurring 3 to 5 weeks after flower initiation. This is close to the amount of time it took the flower buds we observed to undergo the stages leading up to carpel initiation.

Most work documenting the timing of floral bud development in tree species is based on a limited number of samples and authors generally note the first occurrence of any given stage. The present results show that this approach can present a misleading picture of developmental phenology as variation in the timing of developmental events among buds within a tree is extensive. This is seen in the extent of variation that occurs within a cultivar and location (Fig. 6). As these data show, progress of all the buds on a tree through a given stage of development can be greater than the time required for individual buds to move through developmental stages. Therefore, at any given time, there is a highly variable population of buds on the tree.

The extensive within-tree variation precluded a statistical analysis of bud development among years or locations. We found differences among cultivars that can have implications in orchard management. Almond reproductive biology is an important factor in orchard management. Unlike the situation for many tree-fruit species, almonds are not thinned in commercial production, and maximizing fruit set is a high priority. The species is self-incompatible and requires honeybees (Apis mellifera L.) for pollination. Because it is the earliest of the tree-crop species to bloom in California (anthesis typically occurs in late winter), honeybee activity tends to be somewhat weak (Thorpe, 1996). Standard practice is to optimize the potential for cross-pollination by planting three cultivars. The most common orchard design scheme has alternate rows of 'Nonpareil' with adjacent rows of two compatible cultivars whose bloom phenology brackets that of 'Nonpareil.' This design often complicates orchard management as the timing of management practices differ for the different cultivars. Our results show that the relative timing of bud development can be sufficiently variable among cultivars to present another factor to be considered. 
As the data in Table 5 show, at the time of fruit maturation, different cultivars are at different stages in the bud development process. In 'Nonpareil' a greater degree of floral differentiation occurs postharvest than for the other cultivars introducing the possibility that postharvest stresses, such as water stress, may have a greater effect on the following year's flowering in this cultivar.

Sedgley and Griffin (1989) emphasized the importance of knowing the details of the timing of flower initiation and flower development up to anthesis for tree-crop research and management. One example of how this information can be meaningful is in managing reduced irrigation strategies. When available water for orchard irrigation is limited, stress management during critical stages of flower development is essential in order to avoid reduction or loss of the next year's crop. Goldhamer and his colleagues (Almond Board of California, 1999) carried out deficit irrigation research on 'Nonpareil' almonds in the southern San Joaquin Valley. They based their irrigation regimes on the timing of harvest. In the

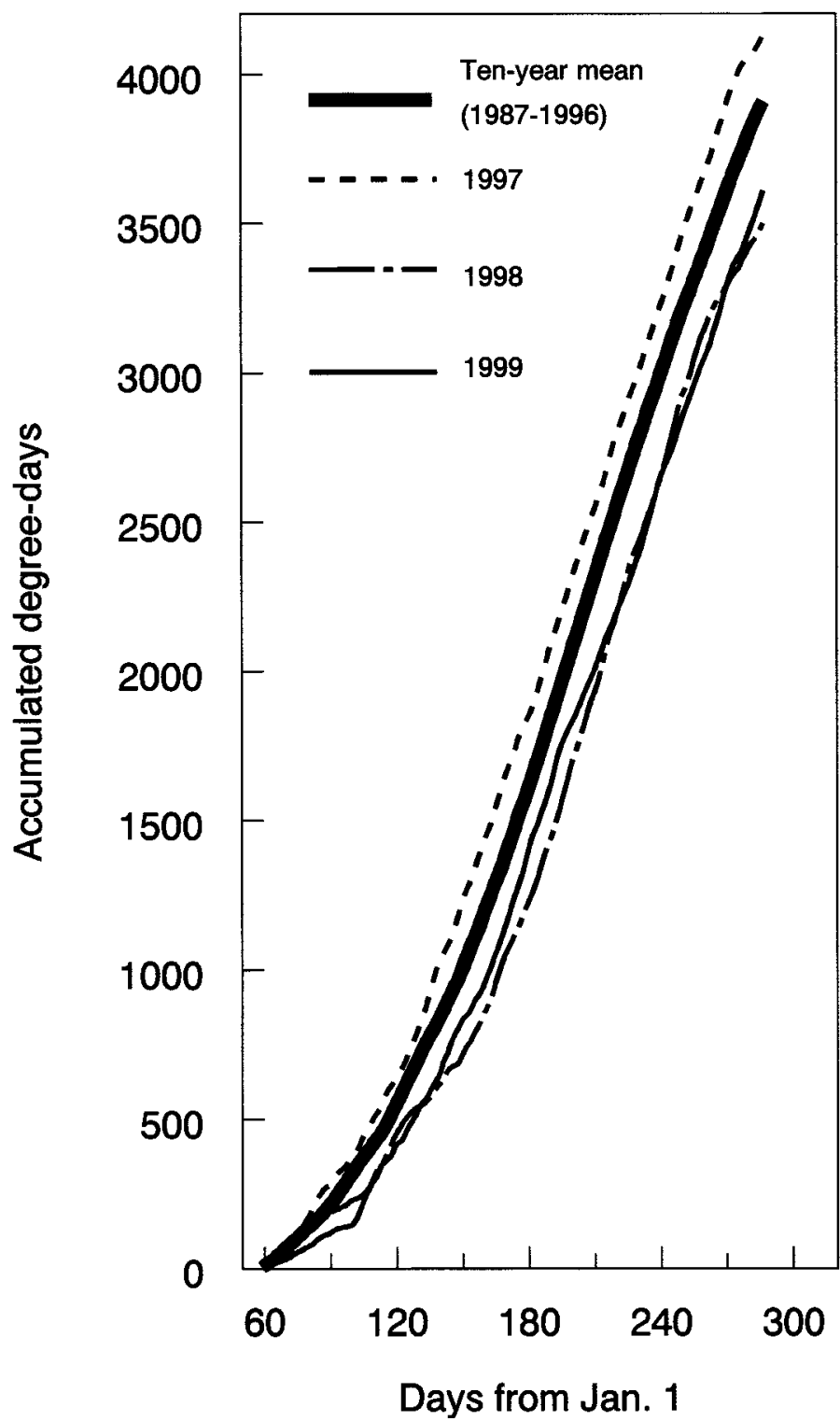

Fig. 5. Temperature patterns for the years of this study at Davis, Calif. Graph shows degree-day accumulation for the period 1 Mar. through 15 Oct. for 1997 99 and the 10-year mean for this period. The general trends shown here (1997 warmer than the mean, and 1998 and 1999 cooler than the mean) were similar in each of the four locations. treatments where irrigation was reduced before harvest but not after harvest, no significant decreases in fruit set occurred the following year. However, when irrigation was terminated after harvest, the next year's flower quality and fruit set were adversely affected, and yields decreased significantly. From data presented herein, we can infer that this postharvest stress was applied while stages of floral differentiation preceding and including carpel initiation were in progress. It is possible that stresses occurring during flower development adversely affected flower quality to the extent that the next
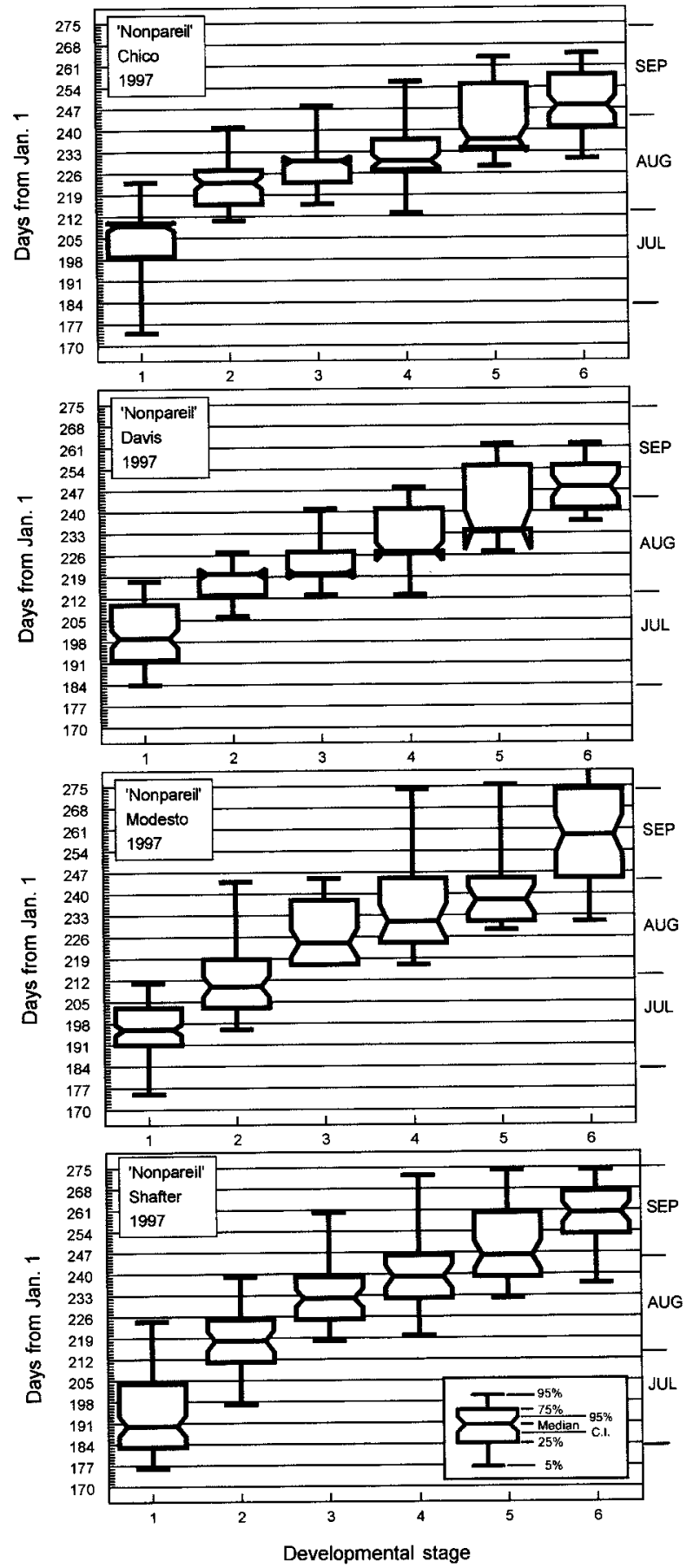

Fig. 6. Box-and-whisker plots showing progress of flower bud development for 'Nonpareil' almond in 1997 at Chico, Davis, Modesto, and Shafter, Calif. The plots show the time for $5 \%, 25 \%, 50 \%, 75 \%$, and $95 \%$ of buds to have attained each of the stages of bud development. Notches indicate $95 \%$ confidence intervals $(95 \%$ C.I. $)$ for the median. 
Table 4. Logistic and probit regression models for flower buds at or beyond stages 1 (flower initiation) and 6 (carpel initiation) of flower development of three almond cultivars in four California locations for 1997 and 1998. Degree-days calculated using 10 and $27{ }^{\circ} \mathrm{C}$ thresholds.

\begin{tabular}{lllrr}
\hline Model & Dependent & Factor & \multicolumn{1}{c}{$\chi^{2}$} & \multicolumn{1}{c}{$P$} \\
\hline Logistic & Stage 1 & Degree-days (DD) & 2164.3 & $<0.0001$ \\
& & Location (L) & 53.3 & 0.0001 \\
& & DD $\times$ L & 11.5 & 0.0094 \\
& & Cultivar (C) & 19.2 & 0.0001 \\
& & DD $\times$ C & 5.2 & 0.0735 \\
& Stage 6 & DD & 3727.8 & $<0.0001$ \\
& & L & 597.2 & 0.0001 \\
Probit & Stage 1 & DD $\times$ L & 34.7 & 0.0001 \\
& & D & 113.3 & 0.0001 \\
& & L $\times$ C & 27.9 & 0.0001 \\
& & DD $\times$ L & 2158.5 & $<0.0001$ \\
& & C & 63.2 & 0.0001 \\
& & DD $\times$ C & 21.9 & 0.0017 \\
& Stage 6 & DD & 0.0001 \\
& & L & 5.7 & 0.0569 \\
& & DD $\times$ L & 590.1 & $<0.0001$ \\
& & C & 32.5 & 0.0001 \\
& & DD $\times$ C & 108.6 & 0.0001 \\
& & & 39.6 & 0.0001 \\
\hline
\end{tabular}

season's crop yield was reduced. We are hopeful that, as one result of the data presented herein, almond researchers can design and interpret experiments such as these with a clearer understanding of the stages of bud development and differentiation that may be affected by their experimental manipulations.

\section{Literature Cited}

Almond Board of California. 1999. Years of discovery: A compendium of research projects 1972 1998. Almond Board of Calif., Modesto, Calif.

Banno, K., S. Hayashi, and K. Tanabe. 1985. Relationships between flower bud formation and endogenous growth regulators in Japanese pear cultivars (Pyrus serotina Rehd.). J. Jpn. Soc. Hort. Sci. 55:258-265.

Bernier, G., J. Kinet, and R.M. Sachs. 1981. The physiology of flowering. vol. 2. CRC Press, Boca Raton, Fla.

Brooks, R.M. 1940. Comparative histogenesis of vegetative and floral apices in Amygdalus communis, with special reference to the carpel. Hilgardia 13:249-299.

Bustamente-Garcia,M.A. 1980. Influence of different irrigation regimes on flowerbud formation and development in peach trees. MS thesis, Univ. of Calif., Davis.

Diaz, D.H., H.P. Rasmussen, and F.G. Dennis, Jr. 1981. Scanning electron microscope examination of flower bud differentiation in sour cherry. J. Amer. Soc. Hort. Sci. 106:513-515.

Guimond, C.M., P.K. Andrews, and G.A. Lang. 1998. Scanning electron microscopy of floral initiation in sweet cherry. J. Amer. Soc. Hort. Sci. 123:509-512.

Luza, J.G. and V.S. Polito. 1988. Microsporogenesis and anther differentiation in Juglans regia L: A developmental basis for heterodichogamy in walnut. Bot. Gaz. 149:30-36.

Micke, W.C., J.H. Connell, P. Verdegaal, M. Viveros, J.T. Yeager, M.A. Thorpe, and T. Gradziel. 1997. Regional almond variety trials. Dept. Pomol., Univ. Calif., Davis.

Micke, W.C., J.H. Connell, P. Verdegaal, M. Viveros, J.T. Yeager, M.A. Thorpe, and T. Gradziel. 1998. Regional almond variety trials. Dept. Pomol., Univ. Calif., Davis.

Polito, V.S. and K. Pinney. 1997. The relationship between phenology of pistillate flower organogenesis and mode of heterodichogamy in Juglans regia L.(Juglandaceae). Sexual Plant Reprod. 10:3639.

Raseira, M.C.B. and J.N. Moore. 1986. Comparison of flower bud initiation in peach cultivars in northern and southern hemispheres. HortScience 21:1367-1368.

Sedgley, M. and A.R. Griffin. 1989. Sexual reproduction of tree crops. Academic Press, London.

Taylor, D.R., P.T. Atkey, M.F. Wickenden, and C.M. Crisp. 1997. A morphological study of flower initiation and development in strawberry (Fragaria $\times$ ananassa) using cryo-scanning electron microscopy. Ann. Appl. Biol. 130:141-152.

Thorpe, R. 1996. Bee management for pollination, p. 132-154. In: W.C. Micke (ed.). Almond production manual. Publ. 3364. Div. Agr. Nat. Sci., Univ. Calif. Oakland, Calif.

Tufts, W.P. and E.B. Morrow. 1925. Fruit bud differentiation in deciduous fruits. Hilgardia 1:1-14. University of California Statewide Integrated Pest Management Project. 2000. Degree-days: Specified thresholds and calculation methods. Degree-Days. 16 June 2000. http:// www.ipm.ucdavis.edu/WEATHER/ddretrieve.html.

Warriner, C.L., J.L. Johnson, and M.W. Smith. 1985. Comparison of the initiation and development of 'Redhaven' peach flowers in standard and meadow orchard trees. J. Amer. Soc. Hort. Sci. 110:379-383

Wetzstein, H.Y. and D. Sparks. 1983. Morphology of pistillate flower differentiation in pecan. J. Amer. Soc. Hort. Sci. 108:997-1003.

Table 5. Time (d) from $10 \%$ or $90 \%$ hull split (HS) to median date for Stages 1 and 6 of bud development for three almond cultivars. ${ }^{\mathrm{Z}}$

\begin{tabular}{|c|c|c|c|c|c|c|}
\hline \multirow[b]{2}{*}{ Cultivar } & \multirow[b]{2}{*}{ Location } & \multirow[b]{2}{*}{ Year } & \multicolumn{2}{|c|}{ Days to Stage 1} & \multicolumn{2}{|c|}{ Days to Stage 6} \\
\hline & & & $10 \% \mathrm{HS}^{\mathrm{y}}$ & $90 \% \mathrm{HS}$ & $10 \% \mathrm{HS}$ & $90 \% \mathrm{HS}$ \\
\hline \multirow[t]{7}{*}{ Nonpareil } & Chico & 1997 & 19 & -16 & 75 & 40 \\
\hline & Modesto & 1997 & 5 & -7 & 61 & 49 \\
\hline & Shafter & 1997 & 36 & -26 & 106 & 44 \\
\hline & Chico & 1998 & 16 & -2 & 59 & 40 \\
\hline & Modesto & 1998 & 35 & 15 & 76 & 56 \\
\hline & Shafter & 1998 & 29 & -8 & 65 & 35 \\
\hline & Median & & 24 & -7.5 & 70 & 42 \\
\hline \multirow[t]{7}{*}{ Carmel } & Chico & 1997 & -23 & -54 & 12 & -19 \\
\hline & Modesto & 1997 & -34 & -32 & 13 & 5 \\
\hline & Shafter & 1997 & -34 & -61 & -2 & 29 \\
\hline & Chico & 1998 & -19 & -30 & 9 & -2 \\
\hline & Modesto & 1998 & -23 & -39 & 5 & -11 \\
\hline & Shafter & 1998 & 5 & -39 & 53 & 3 \\
\hline & Median & & -23 & -39 & 10.5 & 0.5 \\
\hline \multirow[t]{7}{*}{ Butte } & Chico & 1997 & -19 & -27 & 16 & 8 \\
\hline & Modesto & 1997 & -32 & -46 & 26 & 12 \\
\hline & Shafter & 1997 & -7 & -37 & 42 & 12 \\
\hline & Chico & 1998 & -11 & -30 & 31 & 12 \\
\hline & Modesto & 1998 & -16 & -35 & 26 & 7 \\
\hline & Shafter & 1998 & 8 & -34 & 40 & -1 \\
\hline & Median & & -13.5 & -34.5 & 26 & 10 \\
\hline
\end{tabular}

\footnotetext{
${ }^{\mathrm{z}}$ Stages as described in Table 1 .
}

y $\mathrm{HS}=$ hull split. 